\title{
PHYTOCHEMICAL CONTENT AND ANTIOXIDANT ACTIVITIES IN DIFFERENT ORGANS OF POMELO (CITRUS MAXIMA [BURM.] MERR.) USING 2,2-DIPHENYL-1-PICRYLHYDRAZYL AND PHOSPHOMOLYBDENUM ASSAYS
}

\author{
IRDA FIDRIANNY*, ELVIRA SARI, KOMAR RUSLAN
}

Pharmaceutical Biology Research Group, School of Pharmacy, Bandung Institute of Technology, Indonesia. Email: irdafidrianny@gmail. com

Received: 17 June 2016, Revised and Accepted: 11 July 2016

\section{ABSTRACT}

Objectives: The aims of this research were to determine antioxidant activity from various organs extracts of pomelo using 2,2-diphenyl-1picrylhydrazyl (DPPH) and phosphomolybdenum assays, total phenolic, flavonoid, and carotenoid content, correlation of total phenolic, flavonoid, and carotenoid content in various extracts of chayote with their inhibitory concentration $50 \%\left(\mathrm{IC}_{50}\right.$ ) of DPPH antioxidant activities and exhibitory concentration $50 \%\left(\mathrm{EC}_{50}\right)$ of phosphomolybdenum capacity, and correlation between two antioxidant assays.

Methods: Extraction was carried out by reflux using various polarity solvents. The extracts were evaporated using rotary evaporator. Antioxidant activities using DPPH and phosphomolybdenum assays, determination of total phenolic, flavonoid, and carotenoid content were conducted by UVvisible spectrophotometry and its correlation with $\mathrm{IC}_{50}$ of DPPH and $\mathrm{EC}_{50}$ of phosphomolybdenum was analyzed by Pearson's method.

Results: The lowest $\mathrm{IC}_{50}$ of DPPH scavenging activity was shown by ethyl acetate cortex extract of pomelo (0.68 $\left.\mu \mathrm{g} / \mathrm{ml}\right), \mathrm{whereas}$ the lowest EC ${ }_{50}$ of phosphomolybdenum capacity was given by ethyl acetate leaves extract of pomelo (101.36 $\mu \mathrm{g} / \mathrm{ml})$. Ethyl acetate cortex extract of pomelo had the highest total phenolic content and ethyl acetate leaves extract had the highest total flavonoid content (TFC). There was a negative and significant correlation between TFC in cortex and peel extracts of pomelo with their $\mathrm{IC}_{50}$ of DPPH.

Conclusions: All organs extracts of pomelo (except n-hexane peel extract) were classified as a very strong antioxidant by DPPH method. Flavonoid compounds in cortex and peel extract of pomelo were the major contributor in antioxidant activities by DPPH method. DPPH and phosphomolybdenum assays gave no linear results in antioxidant activities of leaves, cortex, and peel extracts of pomelo.

Keywords: Antioxidant, 2,2-diphenyl-1-picrylhydrazyl, Phosphomolybdenum, Pomelo, Three organs.

(C) 2016 The Authors. Published by Innovare Academic Sciences Pvt Ltd. This is an open access article under the CC BY license (http://creativecommons. org/licenses/by/4. 0/) DOI: http://dx.doi.org/10.22159/ajpcr.2016.v9s2.13526

\section{INTRODUCTION}

The excess of reactive oxygen species (ROS) might induce oxidative stress that can contribute to degenerative diseases [1,2]. Previous research reported that phenolic and flavonoid content could be correlated to their antioxidant activities [3-7]. Consumption of fruits and vegetables effective to prevent negative effect of oxidative stress because they have phenolic, flavonoid, and carotenoid compounds $[7,8]$. Reactivity of ROS can be scavenged by antioxidant.

2,2-diphenyl-1-picrylhydrazyl 2,2'-azino-bis (3-ethylbenzthiazoline-6-sulfonic acid) (ABTS), ferric reducing antioxidant power (FRAP), and cupric reducing antioxidant capacity (CUPRAC) can be used to determine antioxidant activity of fruits, vegetables, and food [8-11]. Previous studies [9,12,13]reported that ABTS, DPPH, FRAP, CUPRAC, and phospho- molybdenum methods could be used to determine antioxidant activity in many plants extracts. Plants included pomelo (Citrus maxima) contained phenolic and flavonoid compounds that can act as antioxidant and determination its antioxidant activities had been performed by DPPH, FRAP, and CUPRAC assays [9,14-16].

The objectives of this research were to determine antioxidant activities of various polarities extracts (n-hexane, ethyl acetate, and ethanol) of different organs of pomelo (leaves, cortex, and peel) using DPPH and phosphomolybdenum assays and correlations of total phenolic, flavonoid, and carotenoid content with their antioxidant capacities.

\section{MATERIALS AND METHODS}

\section{Materials}

DPPH, sodium phosphate, ammonium molybdate, gallic acid, quercetin, beta-carotene were purchased from Sigma-Aldrich (MO, USA), three organs of pomelo. All other reagents were analytical grades.

\section{Preparation of sample}

Three organs of pomelo were collected from Subang-West Java, which were leaves namely as LEA, cortex as COR, peel as PEE, were thoroughly washed with tap water, sorted while wet, cut, dried, and grinded into powder.

\section{Extraction}

About $300 \mathrm{~g}$ of powdered samples were extracted by reflux using different polarity solvents. Extraction using n-hexane was repeated three times. The remaining residue was then extracted three times using ethyl acetate. Finally, the remaining residue was extracted three times using ethanol. Therefore, totally there were nine extracts: Three n-hexane extracts (namely LEA1, COR1, and PEE1), three ethyl acetate extracts (LEA2, COR2, and PEE2), and three ethanolic extracts (LEA3, COR3, and PEE3).

Inhibitory concentration $50 \%\left(\mathrm{IC}_{50}\right)$ of DPPH scavenging activity Determination of DPPH scavenging activity was carried out using method from Blois [17] with minor modification. Various concentrations of each extract were pipetted into DPPH solution $50 \mu \mathrm{g} / \mathrm{ml}$ (volume 1:1) to initiate the reaction for creating a calibration curve. After 30 minutes incubation, the absorbance was observed at 
wavelength $515 \mathrm{~nm}$ using a UV-Vis Spectrophotometer Hewlett Packard 8435. Methanol was used as a blank, DPPH solution $50 \mu \mathrm{g} / \mathrm{ml}$ as control and ascorbic acid as standard. The analysis was done in triplicate for each extract and standard. Antioxidant activity was measured by determining the percentage of antioxidant activity using reduction of DPPH absorbance [18]. IC $C_{50}$ of DPPH scavenging activity of each extract can be calculated using its calibration curve.

\section{Exhibitory concentration $50 \%\left(\mathrm{EC}_{50}\right)$ of phosphomolybdenum capacity}

Determination of phosphomolybdenum capacity was performed by Prieto's method [19]. Various concentrations of each extract were pipetted into phosphomolybdenum reagent $50 \mu \mathrm{g} / \mathrm{ml}$ (volume 1:1) to initiate the reaction for figuring a calibration curve. Incubation was carried out at $95^{\circ} \mathrm{C}$ for 90 minutes and cooled 20 minutes; then, absorbance was observed at wavelength $695 \mathrm{~nm}$ using the UV-Vis Spectrophotometer Beckman Coulter DU 720. Aquadest was used as a blank, phosphomolybdenum solution $50 \mu \mathrm{g} / \mathrm{ml}$ which was incubated at $95^{\circ} \mathrm{C}$ for 90 minutes and cooled 20 minutes as control, whereas alphatocopherol incubated at $37^{\circ} \mathrm{C}$ for 90 minutes and cooled 20 minutes as standard. The analysis was conducted in triplicate for each extract and standard. Antioxidant capacity was evaluated based on increasing in phosphomolybdenum complex absorbance by calculating the percentage of antioxidant capacity. $\mathrm{EC}_{50}$ of phosphomolybdenum capacity of each extract can be determined using its calibration curve.

\section{Total phenolic content (TPC) determination}

TPC determination was performed using Folin-Ciocalteu reagent [20]. The absorbance was measured at wavelength $765 \mathrm{~nm}$. Standard solution of gallic acid (55-175 $\mu \mathrm{g} / \mathrm{ml})$ was used to obtain a calibration curve. The analysis was conducted in triplicate for each extract. TPC was represented as a percentage of total gallic acid equivalent per $100 \mathrm{~g}$ extract (g GAE/100 g).

\section{Total flavonoid content (TFC) determination}

Determination of TFC was done using Chang et al. method [21] with minor modification. The absorbance was observed at wavelength $415 \mathrm{~nm}$. Standard solution of quercetin $(30-120 \mu \mathrm{g} / \mathrm{ml})$ was used to obtain a calibration curve. Analysis was carried out in triplicate for each extract. The TFC was exposed as a percentage of total quercetin equivalent per $100 \mathrm{~g}$ extract ( $\mathrm{g} \mathrm{QE} / 100 \mathrm{~g}$ ).

\section{Total carotenoid content (TCC) determination}

TCC determination was measured using modification method from Thaipong et al. [9].Each extract was diluted in $\mathrm{n}$-hexane. The analysis was performed in triplicate for each extract. Standard solution of betacarotene $(40-80 \mu \mathrm{g} / \mathrm{ml})$ was used to obtain a calibration curve. The absorbance was read at wavelength $470 \mathrm{~nm}$. The TCC was revealed as a percentage of total beta-carotene equivalent per $100 \mathrm{~g}$ extract (g BE/100 g).

\section{Statistical analysis}

Each sample analysis was performed in triplicate. All of the presented results are means \pm standard deviation of at least three independent experiments. Statistical analysis using ANOVA with a statistical significance level set at $\mathrm{p}<0.05$ and post-hoc Tukey procedure was conducted with SPSS 16 for Windows. Correlation between the total phenolic, flavonoid, and carotenoid content and antioxidant activities and the correlation between two antioxidant activity methods were performed using the Pearson's method.

\section{RESULTS}

DPPH scavenging activity and phosphomolybdenum capacity The $\mathrm{IC}_{50}$ of DPPH scavenging activities and $\mathrm{EC}_{50}$ of phosphomolybdenum capacities in various organs extracts of pomelo by DPPH and phosphomolybdenum assays were shown in Figs. 1 and 2. $\mathrm{IC}_{50}$ of DPPH scavenging activities of each extract were compared to $\mathrm{IC}_{50}$ ascorbic acid and $\mathrm{EC}_{50}$ of phosphomolybdenum capacity compared to $\mathrm{EC}_{50}$ of alpha-tocopherol as standard. The lowest value of $\mathrm{IC}_{50}$ or $\mathrm{EC}_{50}$ of means had the highest antioxidant activity.

\section{TPC, TFC, and TCC in various organs extracts of pomelo}

TPC among the various organs extracts was presented in term of GAE using the standard curve equation $y=0.005 x-0.016, R^{2}=0.987$. The TPC in various organs extracts of pomelo denoted results varied from 2.62 to $14.8 \mathrm{~g} \mathrm{GAE} / 100 \mathrm{~g}$. The highest phenolic content $(14.8 \mathrm{~g} \mathrm{GAE} / 100 \mathrm{~g}$ ) was given by ethyl acetate cortex extract of pomelo (COR2) followed by ethanolic cortex extract of pomelo (COR3) $13.7 \mathrm{~g} \mathrm{GAE} / 100 \mathrm{~g}$ (Table 1).

TFC among the various organs extracts was stated in term of QE using the standard curve equation $y=0.006 x+0.029, R^{2}=0.998$. The TFC in various organs extracts of pomelo had different results in the range of 1.17-21.28 g QE/100 g (Table 1). Ethyl acetate leaves extract of pomelo (LEA2) had the highest TFC (21.28 g QE/100 g), and the lowest was given by ethanol peels extract of pomelo (PEE3).

TCC among the various extracts was demonstrated in term of BE using the standard curve equation $y=0.012 x-0.178, R^{2}=0.981$. The TCC in various organs extracts of pomelo showed results ranging of 0.07 $24.09 \mathrm{~g} \mathrm{BE} / 100 \mathrm{~g}$ (Table 1). N-hexane leaves extract of pomelo (LEA1) gave the highest carotenoid content (24.09 g BE/100 g), whereas the lowest carotenoid shown by ethanolic cortex extract of pomelo (COR3).

Pearson's correlation coefficient between TFC in different organs of pomelo and their antioxidant activities revealed that TPC in all of the extracts (LEA, COR, and PEE) had significantly negative correlation with their $\mathrm{IC}_{50}$ of DPPH scavenging activities $(\mathrm{r}=-0.736, \mathrm{p}<0.05$; $r=-0.997, p<0.01 ; r=-0.659, p<0.05$, respectively). Meanwhile, TCC in all of sample had a negative and significant correlation with their $\mathrm{EC}_{50}$ phosphomolybdenum capacities (Table 2).

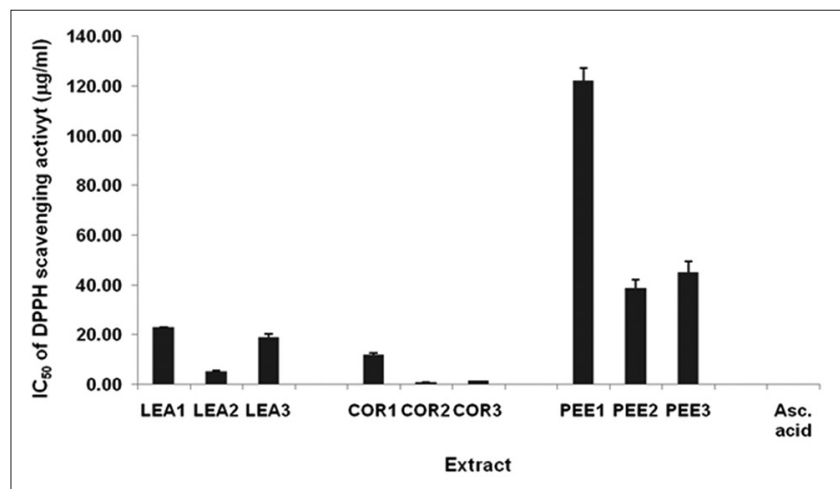

Fig. 1: Inhibitory concentration $50 \%$ of 2,2 -diphenyl-1picrylhydrazyl scavenging activities in various organs extracts of pomelo, $n=3$

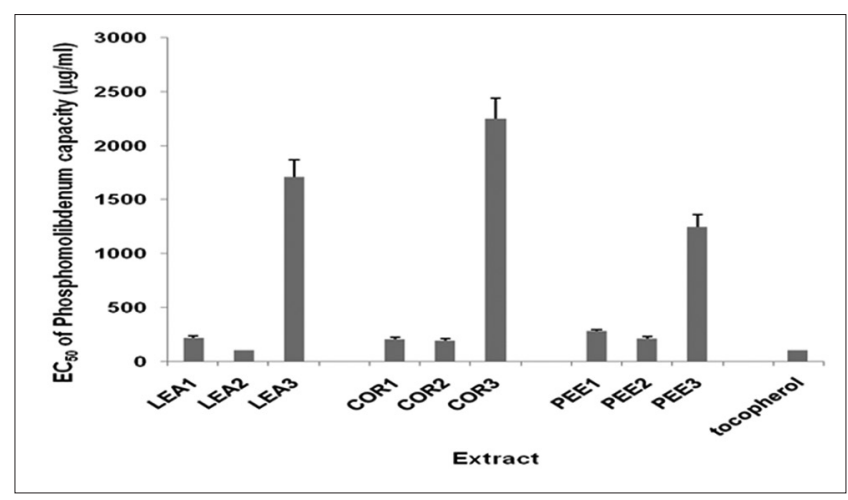

Fig. 2: Exhibitory concentration $50 \%$ of phosphomolybdenum capacities in various organs extracts of pomelo, $n=3$ 
Table 1: TPC, TFC, and TCC in different organs of pomelo

\begin{tabular}{llll}
\hline Sample & TPC (g GAE $/ \mathbf{1 0 0}$ g) & TFC (g QE/100 g) & TCC (g BE/100 g) \\
\hline LEA1 & 4.29 & 8.02 & 24.09 \\
LEA2 & 5.57 & 21.28 & 11.83 \\
LEA3 & 2.99 & 7.3 & 1.74 \\
COR1 & 4.24 & 6.25 & 6.98 \\
COR2 & 14.8 & 9.18 & 2.89 \\
COR3 & 13.7 & 1.52 & 0.07 \\
PEE1 & 2.62 & 3.31 & 5.83 \\
PEE2 & 3.78 & 5.69 & 1.92 \\
PEE3 & 6.88 & 1.17 & 0.39 \\
\hline
\end{tabular}

LEA: Leaves of pomelo, COR: Cortex of pomelo, PEE: Peels of pomelo, 1: n-hexane extract, 2: Ethyl acetate extract, 3: Ethanolic extract, TPC: Total phenolic content, TFC: Total flavonoid content, TCC: Total carotenoid content, GAE: Gallic acid equivalent, QE: Quercetin equivalent, BE: Beta-carotene equivalent

Table 2: Pearson's correlation coefficient of total phenolic, flavonoid, and carotenoid content in different organs of pomelo with their $\mathrm{IC}_{50}$ of DPPH scavenging activities and $\mathrm{EC}_{50}$ of phosphomolybdenum capacities

\begin{tabular}{|c|c|c|c|c|c|c|}
\hline \multirow[t]{2}{*}{ Antioxidant parameter } & \multicolumn{6}{|c|}{ Pearson's correlation coefficient (r) } \\
\hline & TPC & TFC & TCC & IC $_{50}$ DPPH LEA & $\mathrm{IC}_{50}$ DPPH COR & IC $_{50}$ DPPH PEE \\
\hline IC $_{50}$ DPPH LEA & $-0.736^{*}$ & $-0.964^{* *}$ & $0.264 \mathrm{~ns}$ & & & \\
\hline $\mathrm{IC}_{50} \mathrm{DPPH}$ COR & $-0.997 * *$ & $0.071 \mathrm{~ns}$ & $0.886^{* *}$ & & & \\
\hline $\mathrm{IC}_{50}^{50} \mathrm{DPPH}$ PEE & $-0.659 *$ & $-0.100 \mathrm{~ns}$ & $0.937^{* *}$ & & & \\
\hline $\mathrm{EC}_{50}^{50}$ phophomolybd LEA & $-0.892^{* *}$ & $-0.589 n s$ & $-0.795^{*}$ & $0.372 \mathrm{~ns}$ & & \\
\hline $\mathrm{EC}_{50}^{50}$ phophomolybd COR & $0.407 \mathrm{~ns}$ & $-0.922^{* *}$ & $-0.802^{* *}$ & & $-0.438 n s$ & \\
\hline $\mathrm{EC}_{50}^{50}$ phophomolybd PEE & $0.939 * *$ & $-0.872^{* *}$ & $-0.671^{*}$ & & & $-0.375 n s$ \\
\hline
\end{tabular}

$\mathrm{IC}_{50}$ DPPH: IC $\mathrm{IC}_{50}$ DPPH scavenging activity, $\mathrm{EC}_{50}$ phosphomolybd: $\mathrm{EC}_{50}$ phosphomolybdenum capacity, LEA: Leaves of pomelo, COR: Cortex of pomelo, PEE: Peels of pomelo, ns: Not significant, *Significant at p <0.05, ${ }^{*}$ Significant at p <0.01. DPPH: 2,2-diphenyl-1-picrylhydrazyl, IC $_{50}$ : Inhibitory concentration $50 \%$, EC ${ }_{50}$ : Exhibitory concentration $50 \%$

\section{DISCUSSION}

The previous studies [14,15]expressed that pomelo (C. maxima) had antioxidant capacity. There was no study regarding the antioxidant activity of various extracts (which were n-hexane, ethyl acetate, and ethanol) of different organs (leaves, cortex, and peels) of pomelo using DPPH and phosphomolybdenum assays. DPPH free radicals dissolve in methanol give absorption at wavelength $516 \mathrm{~nm}$ Color of DPPH would be changed from purple to yellow when the free radicals were scavenged by antioxidant [22]. Phosphomolybdenum reagent is sodium phosphate which was combined with ammonium molybdate in sulfuric acid solution. Color in phosphomolybdenum method would be changed from colorless to green-blue. Reduction potential of Mo (VI)/Mo (V) is $0.43 \mathrm{~V}$. Intensity of green-blue depends on amount of Mo (VI) that is reduced to Mo (V). Complex Mo (V) - sodium phosphate gives greenblue and shows characteristic absorption at wavelength $695 \mathrm{~nm}$ [19]. The first step of reaction will be produced 12-molybdophosphoric acid (Mo VI) [23]. Antioxidant that has potential lower than $0.43 \mathrm{~V}$ will reduce 12-molybdophosphoric acid (Mo VI) to phosphomolydenum (Mo V) because reduction potential of Mo VI/Mo V is $0.43 \mathrm{~V}$. The absorbance of phosphomolybdenum will be measured at $1695 \mathrm{~nm}$. Increasing in the amount of phosphomolybdenum which was produced will increase the intensity of green-blue and also increase the absorbance.

The present research stated that $\mathrm{IC}_{50}$ of DPPH all of the organs extracts of pomelo in the range of $0.68-122.06 \mu \mathrm{g} / \mathrm{ml}$ and only the $\mathrm{n}$-hexane peels extract had IC $_{50}$ of DPPH more than $50 \mu \mathrm{g} / \mathrm{ml}$ which was $122.06 \mu \mathrm{g} / \mathrm{ml}$ (Fig. 1). The lowest $\mathrm{IC}_{50}$ means showed the highest antioxidant activity. Sample which had $\mathrm{IC}_{50}$ or $\mathrm{EC}_{50}$ lower than $50 \mu \mathrm{g} / \mathrm{ml}$ was a very strong antioxidant, $50-100 \mu \mathrm{g} / \mathrm{ml}$ was a strong antioxidant, $101-150 \mu \mathrm{g} / \mathrm{ml}$ was a medium antioxidant, whereas a weak antioxidant with $\mathrm{IC}_{50}$ or $\mathrm{EC}_{50}>150 \mu \mathrm{g} / \mathrm{ml}$ [17]. Based on the result, it can be concluded all of the organs extracts of pomelo (except $n$-hexane peels extract) can be classified as a very strong antioxidant by DPPH assay and potential as natural antioxidant sources.

The present study demonstrated that the lowest $\mathrm{IC}_{50}$ of DPPH was presented by ethyl acetate cortex extract of pomelo $(0.68 \mu \mathrm{g} / \mathrm{ml})$, meanwhile ascorbic acid as standard had $\mathrm{IC}_{50}$ of DPPH $0.14 \mu \mathrm{g} / \mathrm{ml}$. It can be concluded that potency of ascorbic acid as antioxidant was around five times potency of ethyl acetate cortex extract of pomelo, by DPPH method. The previous research denoted that IC50 of DPPH ethanolic peel extract of Citrus sinensis from three different sites (Kintamani, Jember, and Banyuwangi) were $2.25,8.84,17.94 \mu \mathrm{g} / \mathrm{ml}$, respectively [24]. Itwas different from the present study which represented that ethanolic peel extract of pomelo (C. maxima) from Subang-West Java had IC $_{50}$ of DPPH $44.96 \mu \mathrm{g} / \mathrm{ml}$.

The previous studies revealed that $\mathrm{IC}_{50}$ of DPPH scavenging activities of methanolic peel extract of Citrus limon, $C$. sinensis var. Sungin, $C$. sinensis var. Valencia, and $C$. sinensis var. Navel which was extracted using percolation had $\mathrm{IC}_{50}$ of DPPH 1.4, 1.7, 2.1, and $1.1 \mu \mathrm{g} / \mathrm{ml}$ [25]; ethanolic extract of leaves, peel, and stem of Citrus hystrix from Boyolali - Central Java, Indonesia were $16.6,16.7$, and $7.1 \mu \mathrm{g} / \mathrm{ml}$, respectively [26]. Research by Prasad [15] reported that ethanolic leaves extracts of C. hystrix, Citrus aurantifolia, C. maxima, Citrus reticulata, and Citrus medica had $\mathrm{IC}_{50}$ of DPPH scavenging activities 740, 736, 730, 1070, and $1753 \mu \mathrm{g} / \mathrm{ml}$, respectively. It was contrary to the previous research which showed that $\mathrm{IC}_{50}$ of DPPH scavenging activities of ethanolic leaves extract of $C$. reticulata, $C$. maxima, $C$. limon, $C$. hystrix, and $C$. aurantifolia were $12.76,263.49,4.42,23.27$, and $17.38 \mu \mathrm{g} / \mathrm{ml}$, respectively [14].

The previous study demonstrated that $\mathrm{EC}_{50}$ of FRAP capacity of ethanolic leaves extracts of $C$. reticulata, C. maxima, C. limon, C. hystrix, and $C$. aurantifolia varied from 81.54 to $131.06 \mu \mathrm{g} / \mathrm{ml}$ [14], whereas the present study revealed that $\mathrm{EC}_{50}$ phosphomolybdenum capacity of ethanolic extract of leaves, cortex, and peel extracts of pomelo (C. maxima) were 278.31, 212.19, and $1243.13 \mu \mathrm{g} / \mathrm{ml}$, respectively. Toh et al. [27] exposed that methanolic extracts of peel and pulp of white tambun pomelo gave higher antioxidant activities by FRAP assays (1.01 and $0.42 \mathrm{mmol} F($ II), respectively) than pink tambun pomelo ( 0.65 and $0.51 \mathrm{mmol}$ Fe(II), respectively). The similar result was demonstrated by TEAC assay which showed white tambun pomelo had higher antioxidant activity than pink tambun pomelo. Previous research [28] stated that methanolic extract of small fruit of Citrus grandis "tomentosa" showed higher antioxidant activity by DPPH, FRAP, and ABTS methods (23 $\mu \mathrm{mol}$ trolox equivalent [TE]/g, $149 \mu \mathrm{mol}$ $\mathrm{FeSO}_{4} / \mathrm{g}$, and $58 \mu \mathrm{mol} \mathrm{TE} / \mathrm{g}$, respectively) compared to its medium fruit, 
large fruit, flower, leaves, and branch. A study by Pichaiyongvongdee et al. [29] reported that ethanolic extract of different parts of fruit (flavedo, albedo, segment membranes, and seeds) using seven cultivars of pomelo showed different results in antioxidant activities by DPPH and FRAP methods. Ethanolic seeds extract of pomelo cultivar Kao Paen gave the highest percentage DPPH scavenging activity (85.34\%) while using FRAP assays ethanolic seeds extract of pomelo cultivar Thong Dee exposed the highest antioxidant capacity (2431.31 mg TE/100 ml).

The present research demonstrated that all organs extracts of pomelo (C. maxima) showed $\mathrm{EC}_{50}$ of phosphomolybdenum capacities varied from 101 to $2247 \mu \mathrm{g} / \mathrm{ml}$. The ethyl acetate leaves extract of pomelo (LEA2) gave the lowest $\mathrm{EC}_{50}$ of phosphomolybdenum capacity $101 \mu \mathrm{g} / \mathrm{ml}$, while ascorbic acid had $\mathrm{EC}_{50}$ of phosphomolybdenum capacity $100.65 \mu \mathrm{g} / \mathrm{ml}$. It can be concluded that potency of LEA2 as antioxidant was similar to ascorbic acid, using phosphomolybdenum assay. In the present study, the reagent of antioxidant and sample were prepared in the same volume 1:1. The reagent of DPPH and reagent of 12-molybdophosphoric acid were prepared in concentration $50 \mu \mathrm{g} / \mathrm{ml}$. The first method (DPPH method) showed that $50 \mu \mathrm{g} / \mathrm{ml}$ free radical of DPPH was enough for serving reaction completely and the sample could give lower $\mathrm{IC}_{50}$ of DPPH in varied from 0.68 to $122.06 \mu \mathrm{g} / \mathrm{ml}$. While in the second method (phosphomolybdenum method) sample had high values of $\mathrm{EC}_{50}$ of phosphomolybdenum capacities in the range of 101$2247 \mu \mathrm{g} / \mathrm{ml}$. The values of $\mathrm{EC}_{50}$ phosphomolybdenum capacities were higher than their $\mathrm{IC}_{50}$ of DPPH. Based on the value of $\mathrm{EC}_{50}$ of phosphomolybdenum capacity, it can be supposed that the reagent 12 -molybdophosphoric acid $50 \mu \mathrm{g} / \mathrm{ml}$ was not enough to react with all of antioxidants in the sample. Only a little antioxidant in sample reacted with the reagent, and there were still most of antioxidant in sample, which will oxidize again Mo V to Mo VI. This reaction will be repeated, between reduction from Mo VI to Mo V and then excessive of antioxidant in the sample will oxidize again Mo V to Mo VI. Based on the explanation above, it can be concluded that the high value of $\mathrm{EC}_{50}$ of phosphomolybdenum capacity because there was not enough amount of Mo VI (12-molybdophosphoric acid) and it means for completing reaction in phosphomolybdenum method it needed more than $50 \mu \mathrm{g} / \mathrm{ml}$ of 12-molybdophosphoric acid.

Antioxidant activity can be correlated with phenolic content $[5,6,11]$. The present study revealed that TPC in ethanolic extracts of leaves, cortex, and peel extracts of pomelo (C. maxima) were 2.99, 13.7, and $6.88 \mathrm{~g} \mathrm{GAE} / 100 \mathrm{~g}$, respectively. It was similar to the previous study [14] regarding citrus leaves extracts, which exposed that TPC in ethanolic leaves extract of $C$. reticulata, $C$. maxima, C. limon, $C$. hystrix and C. aurantifolia from West Java-Indonesia were 5.30, 4.55, 3.31, 3.66, and $6.33 \mathrm{~g} \mathrm{GAE} / 100 \mathrm{~g}$, respectively. It was contrary to the previous study which expressed that TPC in fruit juice of $C$. hystrix and C. aurantifolia, and C. sinensis were 490, 211, and $135 \mathrm{mg} \mathrm{GAE} / 100 \mathrm{ml}$ juice, respectively [30]. Previous research stated that TPC in methanolic peel extract of white tambun pomelo showed higher TPC (406.65 mg GAE $/ 100 \mathrm{~g}$ ) compared to its peel and pulp extracts of pink tambun pome [27]. Research by Hayat [31] exhibited that TPC in methanolic peel extract of $C$. reticulata using the microwave-assisted extraction was $17.5 \mathrm{mg} \mathrm{GAE} / 100 \mathrm{~g}$ and TPC in methanolic peel extracts of $C$. sinensis and $C$. reticulata by ultrasound-assisted extraction method were 6.64 and $5.87 \mathrm{~g} \mathrm{GAE} / 100 \mathrm{~g}$, respectively. The similar results were reported in previous studies which represented that TPC in ethanolic peel extract of $C$. hystrix was $4.4 \mathrm{~g} \mathrm{GAE} / 100 \mathrm{~g}$ [26]; TPC in methanolic peel extracts of $C$. sinensis var. Washington Navel, $C$. sinensis var. Sungin, $C$. sinensis var. Valencia were 16, 15.4, and $13.3 \mathrm{~g} \mathrm{GAE} / 100 \mathrm{~g}$, respectively [25]; TPC in ethanolic peel extracts of $C$. sinensis from Kintamani, Jember and Banyuwangi were $10.08,8.85$, and $9.54 \mathrm{~g} \mathrm{GAE} / 100 \mathrm{~g}$, respectively [24], and methanolic peel extract of $C$. limon was $13.1 \mathrm{~g} \mathrm{GAE} / 100 \mathrm{~g}$ [25]. Research by Pichaiyongvongdee [29] presented that TPC in ethanolic seed extract of pomelo cultivar Thong Dee had the highest TPC ( $495 \mathrm{mg} / 100 \mathrm{~g}$ ) among different parts of fruit from seven cultivars of pomelo, whereas Duan [28] figured that methanolic small fruit extract of $C$. grandis gave the highest TPC (105 mg GAE/g) compared to its medium fruit, large fruit, flower, leaves, and branch.

The previous research reported that TFC in ethanolic leaves extracts of $C$. reticulata, C. maxima, C. limon, C. hystrix, and C. aurantifolia were $5.44,3.99,3.97,4.46$, and $4.81 \mathrm{~g} \mathrm{QE} / 100 \mathrm{~g}$, respectively [14], whereas the present study revealed that TFC in ethanolic extracts of cortex, peel, and leaves of pomelo (C. maxima) were 1.52, 1.17, and $7.3 \mathrm{~g} \mathrm{QE} / 100 \mathrm{~g}$, respectively. A study by Ghafar [30] showed that TFC in fruit juice of C. hystrix, C. aurantifolia, Citrus Microcarpa, and C. sinensis were $22.25,10.67,8.77$, and $2.99 \mathrm{mg} \mathrm{QE} / 100 \mathrm{ml}$ juice, whereas TFC in methanolic extracts of peel and pulp of white tambun pomelo and pink tambun pomelo were 356.95, 13.06 and 228.86, $13.20 \mathrm{mg} \mathrm{QE} / 100 \mathrm{~g}$, respectively [27]. Previous research demonstrated that TFC in ethanolic leaves extract of $C$. hystrix $(3.0 \mathrm{~g} \mathrm{QE} / 100 \mathrm{~g}$ ) was higher than its peel and stem extracts 1.3 and $0.9 \mathrm{~g} \mathrm{QE} / 100 \mathrm{~g}$ [26]. Study by Ghasemi [25] stated that TFC in methanolic peel extracts of $C$. sinensis var. Washington Navel $2.3 \mathrm{~g} \mathrm{QE} / 100 \mathrm{~g}$ was higher than $C$. sinensis var. Sungin $0.21 \mathrm{~g} \mathrm{QE} / 100 \mathrm{~g}$ and $C$. sinensis var. Valencia $0.72 \mathrm{~g} \mathrm{QE} / 100 \mathrm{~g}$. whereas TFC in ethanolic peel extract of $C$. sinensis from Jember $(1.50 \mathrm{~g} \mathrm{QE} / 100 \mathrm{~g})$ was higher than C. sinensis from Kintamani (1.22 g QE/100 g) and Banyuwangi (0.93 g QE/100 g) [24].

The present research revealed that ethanolic extracts of peel, cortex, and leaves of C. maxima had TCC 0.39, 0.07, and $1.74 \mathrm{~g} \mathrm{BE} / 100 \mathrm{~g}$, respectively. It was similar to the previous study which exposed that TCC in leaves extracts of C. reticulata, C. maxima, C. limon, C. hystrix, and C. aurantifolia from West Java-Indonesia were $0.56,072,0.19,0.36$, and $0.05 \mathrm{~g} \mathrm{BE} / 100 \mathrm{~g}$, respectively [14]. The previous studies expressed that TCC in ethanolic peel extracts of $C$. sinensis from Kintamani, Jember, and Banyuwangi were 37, 21, and $22 \mathrm{mg} \mathrm{BE} / 100$ g, respectively [24], and TCC in all of the ethanolic peel, leaves, and stem extracts of $C$. hystrix from Boyolali, Central Java-Indonesia were $0.2 \mathrm{~g} \mathrm{BE} / 100 \mathrm{~g}$ extract [26].

Pearson's correlation coefficient was significantly negative if $-0.61 \leq \mathrm{r} \leq-0.97$ and significantly positive high if $0.61 \leq \mathrm{r} \leq 0.97$ [9]. The sample which had the lowest IC $_{50}$ of DPPH scavenging activity and $\mathrm{EC}_{50}$ of phosphomolybdenum capacity gave the highest antioxidant activity. Therefore, significantly negative correlation will be shown in a good correlation between TPC, TFC, and TCC with $\mathrm{IC}_{50}$ of DPPH or $\mathrm{EC}_{50}$ of phosphomolybdenum [26]. It means increasing in TFC, TPC, and TCC would increase antioxidant activities, which was expressed by lower $\mathrm{IC}_{50}$ of DPPH scavenging activity and or $\mathrm{EC}_{50}$ of phosphomolybdenum capacity.

The significant and negative correlation between TPC in peel and cortex extracts of $C$. maxima and $\mathrm{IC}_{50}$ of DPPH can be seen in Table 2 ( $\mathrm{r}=-0.659$, $\mathrm{p}<0.05 ; \mathrm{r}=-0.997, \mathrm{p}<0.01)$. Based on the result, it can be suggested that phenolic compounds in peel and cortex of $C$. maxima were the mayor contributor in their antioxidant activity by DPPH assay. Previous studies demonstrated that TPC in C. aurantifolia leaves extracts, and its $\mathrm{IC}_{50}$ of DPPH scavenging activities had significant and negative correlation $(\mathrm{r}=-0.983, \mathrm{p}<0.01)$ and also with its $\mathrm{EC}_{50}$ of FRAP capacities $(\mathrm{r}=-0.974$, $\mathrm{p}<0.01$ ) [14]. It can be concluded that phenolic compounds were the major contributor in antioxidant activities of $C$. aurantifolia leaves extract using DPPH, FRAP assays. There was significantly negative correlation also between TFC, TCC in leaves, peel and stem extracts of C. hystrix with their $\mathrm{EC}_{50}$ of CUPRAC capacities [26]. It was similar to the present research which exposed that TFC and TCC in cortex extract of C. maxima had a significant and negative correlation with its $\mathrm{EC}_{50}$ of phosphomolybdenum.

In previous research, the Pearson's correlation was analyzed between TPC, TFC, and TCC with their percentage of DPPH scavenging activities [24]. Therefore, the good correlation between TPC, TFC, and or TCC with the percentage of DPPH scavenging activity or percentage of FRAP capacity when there was a positive and high correlation. The previous result [24] stated that TPC in peel extracts of $C$. sinensis from Kintamani, Jember, and Banyuwangi were significantly positive 
correlation with their percentage of DPPH scavenging activities. A study by Toh [27] reported that TPC and TFC of pomelo pulp and peel had negative and significant correlation with their antioxidant activity using FRAP assay, which was exposed in mmol Fe(II)/100 g, and significantly positive correlation with their antioxidant activity by TEAC assay, which presented in mmol TE/100 g. Ghafar [30] revealed that there was a positive and significant correlation between TPC in fruit juice of C. aurantifolia with its percentage of FRAP capacity, but there was no correlation with its percentage of DPPH scavenging activity.

Phenolic groups in plant included phenolic acid, flavonoid, tannins, qoumarine, and quinone. In Table 1 , it can be seen that TPC in ethanolic peel extract of pomelo (PEE3) $6.88 \mathrm{~g} \mathrm{GAE} / 100 \mathrm{~g}$ was higher than TPC in ethanolic leaves extract of pomelo (LEA3) $2.99 \mathrm{~g}$ GAE/100 g, but LEA3 had high antioxidant activity which showed by lower $\mathrm{IC}_{50}$ of DPPH $(18.93 \mu \mathrm{g} / \mathrm{ml})$ than $\mathrm{IC}_{50}$ of DPPH PEE3 $(44.96 \mu \mathrm{g} / \mathrm{ml})$. Heim [32] stated that cinnamic acid had higher antioxidant activity compared to benzoic acid and phenylacetic acid. It can be predicted that LEA3 contained many phenolic compounds which had high antioxidant activity. Meanwhile, PEE3 contained many phenolic compounds with low antioxidant activity.

TFC in ethanolic cortex extract of pomelo (COR3) $1.52 \mathrm{~g} \mathrm{QE} / 100 \mathrm{~g}$ was similar to TFC in ethanolic peel extract of pomelo (PEE3) $1.17 \mathrm{~g}$ QE/100 g; however, IC I0 $_{0}$ of DPPH COR3 $(1.46 \mu \mathrm{g} / \mathrm{ml})$ was lower than $\mathrm{IC}_{50}$ of DPPH PEE3 $(44.96 \mu \mathrm{g} / \mathrm{ml})$. Flavonoid compound which has $\mathrm{OH}$ in A ring and or B ring will be included in phenolic groups. Flavonoid had higher antioxidant activity than phenolic acid [32]. Flavonoid which had ortho diOH at C-3', C-4, $\mathrm{OH}$ at C-3, oxo function at C-4, double bond at C-2 - C-3 have high antioxidant activity. The diOH with ortho position at C-3'-C-4' had the highest influence to the antioxidant activity of flavonoid. The flavonoid aglycones would give higher antioxidant activity than flavonoid glycosides [32]. Based on the results above, it can be suggested that COR3 contained many flavonoid compounds that had $\mathrm{OH}$ at position above, which had high antioxidant activity, whereas PEE3 contained many flavonoid compounds which had $\mathrm{OH}$ at C-5 or C-7 or only C-3' or only C-4', or without double bond at C-2-C-3, or without $\mathrm{OH}$ at $\mathrm{C}-3$, which had low antioxidant activity.

The previous study exposed that carotenoid has the antioxidant capacity by scavenging free radical [33]. It can scavenge free radical because it consists of many double bonds. Carotenoid would give higher scavenging radical activity if contain $>7$ double bonds [34]. Betacarotene can be used as standard because it has conjugation double bonds which have the ability to scavenge free radicals [35]. TCC in n-hexane leaves extract of pomelo (LEA1) $24.09 \mathrm{~g} \mathrm{BE} / 100 \mathrm{~g}$ was higher than TCC in n-hexane cortex extract of pomelo (COR1) $6.98 \mathrm{~g} \mathrm{BE} / 100 \mathrm{~g}$; however, IC $_{50}$ of DPPH COR1 $(12.03 \mu \mathrm{g} / \mathrm{ml})$ was lower than $\mathrm{IC}_{50}$ of DPPH LEA1 $(22.82 \mu \mathrm{g} / \mathrm{ml})$. Increasing in antioxidant activity which is shown by lower IC $_{50}$ of DPPH scavenging activity will be given by increasing in lipophilicity of carotenoid [36]. It can be predicted that many carotenoid compounds in COR1 had more than 7 double bonds, whereas many carotenoid compounds in LEA1 had maximum 7 double bonds.

TFC in n-hexane leaves extract of pomelo (LEA1) $8.02 \mathrm{~g} \mathrm{QE} / 100 \mathrm{~g}$ was higher than TFC in ethyl acetate peel extract of pomelo (PEE2) $5.69 \mathrm{~g}$ QE/100 g; however, $\mathrm{EC}_{50}$ of phosphomolydenum LEA1 $(216.51 \mu \mathrm{g} / \mathrm{ml})$ was similar to $\mathrm{EC}_{50}$ of phosphomolydenum PEE2 (212.19 $\left.\mu \mathrm{g} / \mathrm{ml}\right)$. Sample will act as antioxidant in phosphomolybdenum assay if sample had reduction potential lower than reduction potential of Mo (VI) to Mo (V) $0.43 \mathrm{~V}$. Based on the results, it can be suggested that LEA1 and PEE2 contained the similar amount of flavonoid compounds which had reduction potential lower than $0.43 \mathrm{~V}$.

Pearson's correlation was used to analyze the correlation between two antioxidant methods. The good correlation between two methods if there was a positive and significant correlation between one method to the other method. There was no correlation between $\mathrm{IC}_{50}$ of $\mathrm{DPPH}$ and $\mathrm{EC}_{50}$ of phosphomolybdenum in all of the pomelo organs extracts. It could be seen DPPH method gave no linear results with phosphomolybdenum method in antioxidant activity of pomelo organs extracts.

\section{CONCLUSION}

Various antioxidant assays could give different results. Therefore, the antioxidant activity of sample should be determined by different assays in parallel. All of the pomelo organs extracts (except n-hexane peel extract of pomelo) can be classified as very strong antioxidant by DPPH method. TPC in cortex and peel extracts of pomelo had a significant and negative correlation with their $\mathrm{IC}_{50}$ of DPPH scavenging activities. Antioxidant activity of pomelo cortex and peel extracts by DPPH method can be estimated using its TPC data. DPPH and phosphomolybdenum assays showed no linear results for antioxidant activity in all of the pomelo organs extracts. Leaves, cortex, and peel of $C$. maxima may be exploited as sources of natural antioxidant.

\section{REFERENCES}

1. Gramza-Michalowska A, Czlapka-Matyasik M. Evaluation of the antiradical potential of fruit and vegetable snacks. Acta Sci Pol Technol Aliment 2011;10(1):63-72.

2. Sharma P, Jha AB, Dubey RS, Pessarakli M. Reactive oxygen species, oxidative damage, and antioxidative defense mechanism in plants under stressful conditions. J Bot 2012;2012:1-26.

3. Apak R, Gorinstein S, Böhm VK, Schaich MK. Methods of measurement and evaluation of natural antioxidant capacity/activity: IUPAC technical report. Pure Appl Chem 2013;85:957-98.

4. Mohan M, Jaiswal BS, Kasture S. Effect of Solanum torvum on blood pressure and metabolic alterations in fructose hypertensive rats. J Ethnopharmacol 2009;126(1):86-9.

5. Khatua S, Roy T, Acharya K. Antioxidant and free radical scavenging capacity of phenolic extract from Russula laurocerasi. Asian J Pharm Clin Res 2013;6(4):156-60.

6. $\mathrm{Xu}$ BJ, Chang SK. A comparative study on phenolic profiles and antioxidant activities of legumes as affected by extraction solvents. J Food Sci 2007;72(2):S159-66.

7. Xu BJ, Chang SK. Total phenolic content and antioxidant properties of eclipse black beans (Phaseolus vulgaris L.) as affected by processing methods. J Food Sci 2008;73(2):H19-27.

8. Pellegrini N, Serafini M, Colombi B, Del Rio D, Salvatore S, Bianchi M, et al. Total antioxidant capacity of plant foods, beverages and oils consumed in Italy assessed by three different in vitro assays. J Nutr 2003;133(9):2812-9.

9. Thaipong K, Boonprakob U, Crosby K, Zevallos LC, Byrne DH. Comparison of ABTS, DPPH, FRAP, and ORAC assays for estimating antioxidant activity from guava fruit extracts. J Food Comp Anal 2006;19:669-75.

10. Ordonez AA, Gomez JD, Vattuane MA, Isla MI. Antioxidant activities of Sechium edule (Jacq.) Swartz extracts. Food Chem 2006;97:452-8.

11. Win M, Hamid A, Baharin B, Anwar FS, Pak-Dek MS. Phenolic compounds and antioxidant activity of peanut's skin, hull, raw kernel and roasted kernel flour. Pak J Bot 2011;43(3):1635-42.

12. Fidrianny I, Darmawati A, Sukrasno. Antioxidant capacities from different polarities extracts of Cucurbitaceae leaves using FRAP, DPPH assays and correlation with phenolic, flavonoid, carotenoid content. Int J Pharm Pharm Sci 2014;6(2):858-62.

13. Apak R, Kubilay G, Birsen D, Mustava O, Saliha EC, Burcu B, et al. Comparative evaluation of different polarities total antioxidant capacity assays applied to phenolic compounds with the CUPRAC assay. Molecules 2007;12:1496-547.

14. Fidrianny I, Amaliah A, Sukrasno. Antioxidant activities evaluation of citrus leaves extracts from West Java-Indonesia using DPPH and FRAP assays. Int J Pharmacog Phytochem Res 2016;8(4):611-8.

15. Prasad MP, Rajkumar RA. In vitro antioxidant assay of citrus species using DPPH method. Indian J Adv Plant Res 2014;1(4):1-3.

16. Mashkor IM. Phenolic content and antioxidant activity of fenugreek seeds extract. Int J Pharmacogn Phytochem Res 2014;6(4):841-4.

17. Blois MS. Antioxidant determination by the use of stable free radicals. Nature 1958;181:1199-2000.

18. Bedawey AA. Characteristics of Antioxidant Isolated from Some Plants Sources. Cairo: Shibin El-Kom; 2010. p. 1-11.

19. Prieto P, Pineda M, Aguilar M. Spectrophotometric quantitation of antioxidant capacity through the formation of a phosphomolybdenum 
complex: Specific application to the determination of Vitamin E. Anal Biochem 1999;269(2):337-41.

20. Pourmorad F, Hosseinimehr SJ, Shahabimajd N. Antioxidant activity, phenol and flavonoid content of some selected Iranian medicinal plants. Afr J Biotechnol 2006;5(11):1142-5.

21. Chang CC, Yang MH, Wen HM, Chern JC. Estimation of total flavonoid content in propolis by two complementary colorimetric methods. J Food Drug Anal 2002;10:178-82.

22. Li XC, Wang XZ, Chen DF, Chen SZ. Antioxidant activity and mechanism of protochatechuic acid in vitro. J Funct Food Health Dis 2011;1:232-44

23. Crouch SR, Malmstadt HV. A mechanistic investigation of molybdenum blue method for determination of phosphate. Analyt Chem 1967;39(10):1084-9.

24. Fidrianny I, Harnovi M, Insanu M. Evaluation of antioxidant activities from various extracts of sweet orange peels using DPPH. Asian J Pharm Clin Res 2014;7(3):186-90.

25. Ghasemi K, Ghasemi Y, Ebrahimzadeh MA. Antioxidant activity, phenol and flavonoid contents of 13 citrus species peels and tissues. Pak J Pharm Sci 2009;22(3):277-81.

26. Fidrianny I, Johan Y, Sukrasno. Antioxidant activities of differen polarity extracts from three organs of makrut lime (Citrus hystrix DC) and correlation with total flavonoid, phenolic, carotenoid content. Asian J Pharm Clin Res 2015;8(4):239-43.

27. Toh JJ, Khoo HE, Azrina A. Comparison of antioxidant properties of pomelo (Citrus grandis (L) Osbeck) varieties. Int Food Res J 2013;20(4):1661-8
28. Duan L, Guo L, Dou LL, Yu KY, Liu EH, Li P. Comparison of chemical profiling and antioxidant activities of fruits, leaves, branches, and flowers of Citrus grandis "Tomentosa". J Agric Food Chem 2014;62:11122-9.

29. Pichaiyongvongdee S, Rattanapun B, Haruenki R. Total polypheno content and antioxidant properties in different tissues of seven pomelo (Citrus grandis (L.) Osbeck) cultivars. Kasetsart J Nat Sci 2014;48:989-96.

30. Ghafar MFA, Prasad KN, Weng KK, Ismail A. Flavonoid, hesperidine, total phenolic contents and antioxidant activities from Citrus species Afr J Biotechnol 2010;9(3):326-30.

31. Hayat K, Hussain S, Abbas S, Farooq U, Ding B, Xia S, et al. Optimized microwave-assisted extraction of phenolic acids from citrus mandarin peels and evaluation of antioxidant activity in vitro. Sep Purif Technol 2009;70:63-70.

32. Heim KE, Tagliaferro AR, Bobilya DJ. Flavonoid antioxidants Chemistry, metabolism and structure-activity relationships. J Nutr Biochem 2002;13(10):572-584

33. Foote CS. Free Radicals in Biology. $3^{\text {rd }}$ ed. New York: Academic Press 1976.

34. Beutner S, Bloedorn B, Hoffmann T, Martin HD. Synthetic singlet oxygen quenchers. Methods Enzymol 2000;319:226-41.

35. Charles DJ. Antioxidant Properties of Spices Shells and Other. London: John Willey; 2013.

36. Kobayashi M, Sakamoto Y. Singlet oxygen quenching ability of astaxanthin esters from the green alga Haematococcus pluvialis. Biotechnol Lett 1999;21:265-9. 